\title{
Intermodal Raman Scattering between Full Vectorial Modes in Few Moded Fiber
}

\author{
Rishøj, Lars Søgaard; Ramachandran, Siddharth; Rottwitt, Karsten
}

Published in:

Proceedings of 2013 Conference on Lasers and Electro-Optics (CLEO)

Publication date:

2013

Document Version

Publisher's PDF, also known as Version of record

Link back to DTU Orbit

Citation (APA):

Rishøj, L. S., Ramachandran, S., \& Rottwitt, K. (2013). Intermodal Raman Scattering between Full Vectorial Modes in Few Moded Fiber. In Proceedings of 2013 Conference on Lasers and Electro-Optics (CLEO) (pp. CTU3K.2). IEEE.

\section{General rights}

Copyright and moral rights for the publications made accessible in the public portal are retained by the authors and/or other copyright owners and it is a condition of accessing publications that users recognise and abide by the legal requirements associated with these rights.

- Users may download and print one copy of any publication from the public portal for the purpose of private study or research.

- You may not further distribute the material or use it for any profit-making activity or commercial gain

- You may freely distribute the URL identifying the publication in the public portal

If you believe that this document breaches copyright please contact us providing details, and we will remove access to the work immediately and investigate your claim. 


\title{
Intermodal Raman Scattering between Full Vectorial Modes in Few Moded Fiber
}

\author{
Lars Rishøj ${ }^{1, *}$, Siddharth Ramachandran ${ }^{2}$, and Karsten Rottwitt ${ }^{1}$ \\ ${ }^{1}$ Technical University of Denmark, Ørsteds plads 343, 2800 Kgs. Lyngby, Denmark \\ ${ }^{2}$ Boston University, Dept. of Electrical and Computer Engineering, 8 Saint Mary's St., Boston, MA 02215, USA \\ ${ }^{*}$ Corresponding author: lris@fotonik.dtu.dk
}

\begin{abstract}
We experimentally investigate intermodal Raman interaction. The pump is in the fundamental mode, $\mathrm{HE}_{11}$, and the signal is in either of two full vectorial modes, $\mathrm{TM}_{01}$ or $\mathrm{TE}_{01}$. The on-off gain is approximately $3 \mathrm{~dB}$ for both modes, using $4 \mathrm{~km}$ of few-moded fiber and $400 \mathrm{~mW}$ of pump power.
\end{abstract}

(C) 2013 Optical Society of America

OCIS codes: 190.4370 (Nonlinear optics, fibers); 190.5650 (Raman effect).

Over recent years intermodal Raman scattering has received increasing attention. The interaction between linear polarized psedomodes in a hollow-core photonic crystal fiber (PCF) was studied in [1]. Previously, spontaneous Raman scattering was utilized in the fiber used in this paper to generate vortex beams over a broad wavelength range by pumping at $1064 \mathrm{~nm}$ [2]. Furthermore, spacial division multiplexing (SDM) has been proposed as a mean to expand the optical communication bandwidth, either using multi-core fibers (MCFs) or few-moded fibers (FMFs). For long-haul communication optical amplification is crucial, in this regard FMFs has the advantage of intensity overlap between the different modes, which enables sharing of a single pump between multiple signal modes [3]. In this paper measurements of intermodal Raman scattering is presented for a $4 \mathrm{~km}$ specialty designed fiber [4]. The pump is in the fundamental mode, $\mathrm{HE}_{11}$, whereas the signal is in $\mathrm{HE}_{11}$ or either of the two full vectorial modes, $\mathrm{TM}_{01}$ or $\mathrm{TE}_{01}$.

The schematics of the experimental setup is provided in Fig. 1a. The mode excitation is performed using a long

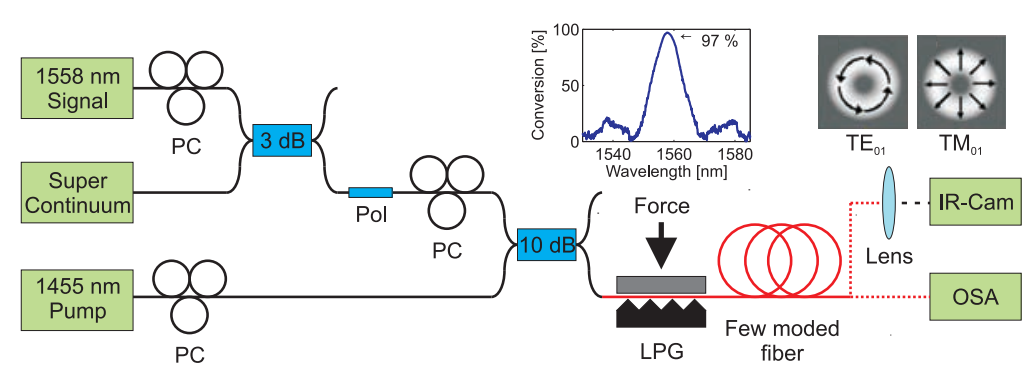

(a)

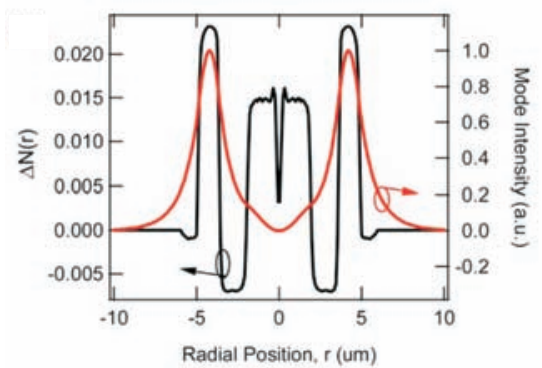

(b)

Fig. 1: (a) Schematics of the experimental setup. (b) Index profile (black) for few moded fiber, and the radial intensity profile for $\mathrm{TE}_{01}$ (red).

period microbend grating (LPG). The grating is created by pressing an aluminium block with periodic grooves and a rubber pad together. The supercontinuum source is used to optimize the mode coupling by adjusting the polarization controller (PC) after the polarizer (pol) and the pressure on the fiber. Insets are provided of the two modes of interest, where the arrows indicate the polarization of the mode. The inserted graph shows a typical conversion spectrum; in this example the maximum conversion from $\mathrm{HE}_{11}$ to $\mathrm{TE}_{01}$ is approximately $97 \%$. After the seed signal at $1558 \mathrm{~nm}$, the pump at $1455 \mathrm{~nm}$, and the supercontinuum source are combined the FMF (red) is spliced to the SMF (black). The output of the FMF is either measured with an OSA or imaged on an IR-camera. The index profile of the FMF is seen in Fig. 1b. The fiber design eliminates the degeneracy of the first mode group consisting of $\mathrm{TM}_{01}$ (radially polarized), $\mathrm{TE}_{01}$ (azimuthally polarized), and the two degenerated modes $\mathrm{HE}_{21}$ (mixed polarized). Therefore strong mode coupling between this first mode group yielding the familiar $\mathrm{LP}_{11}$ mode is avoided, and controlled excitation of the individual full vectorial modes is ensured, together with stable propagation along the fiber [4]. The loss for $\mathrm{HE}_{11}$ was measured at $1.4 \mathrm{~dB} / \mathrm{km}$, whereas for $\mathrm{TM}_{01}$ and $\mathrm{TE}_{01}$ it was $1.6 \mathrm{~dB} / \mathrm{km}$. The rather high loss is a consequence of the large index steps in the fiber design, which are needed to eliminate the degeneracy. 
The on-off Raman gain as a function of pump power is shown in Fig. 2a. The pump is in the fundamental mode, $\mathrm{HE}_{11}$, whereas the signal is in either $\mathrm{HE}_{11}, \mathrm{TM}_{01}$, or $\mathrm{TE}_{01}$ as indicated by the legend. Each measurement is carried out over $100 \mathrm{~s}$; an example of a measurement is shown in Fig. 2b (blue line). The fluctuations in power are caused by interference between different modes in the fiber. The fluctuations are significantly smaller for $2 \mathrm{~m}$ of FMF (green line); this indicates that the parasitic modes are primarily excited by undesired mode propagation instability over the long length of the fiber. For $2 \mathrm{~m}$ of fiber the main contribution is from conversion at the splice point. In Fig. 2a the line denotes the average power and the error-bars indicates one standard deviation. The smaller error-bars for $\mathrm{HE}_{11}$ indicate larger mode stability, which is expected since the difference in propagation constant is largest between the fundamental mode and all remaining modes in the fiber. The process of Raman scattering depends primarily on the

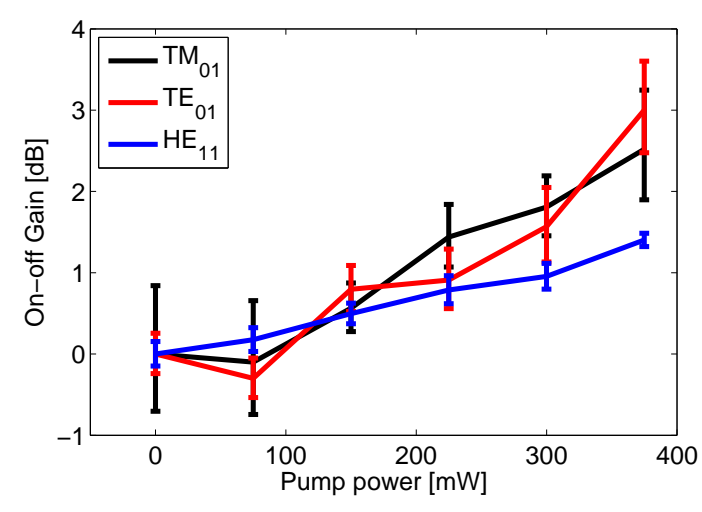

(a)

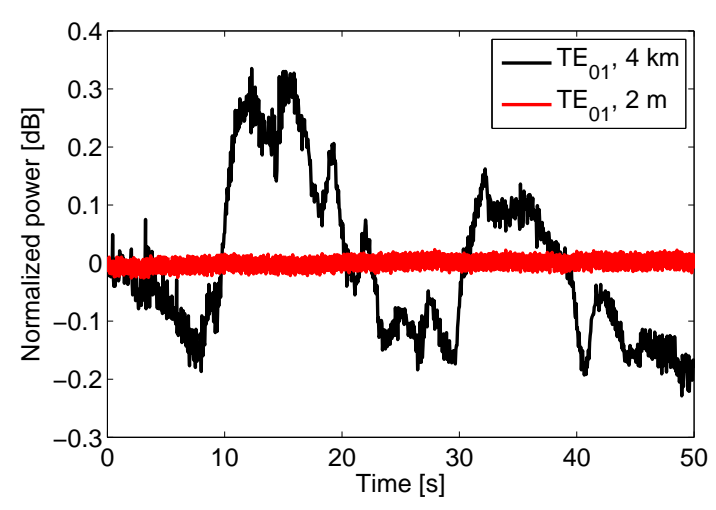

(b)

Fig. 2: (a) Intermodal Raman gain as a function of pump power. (b) Power as a function of time for different fiber lengths.

co-polarized intensity overlap integral between the modes. The inverse of this integral yield an effective Raman area, between the fundamental mode at $1455 \mathrm{~nm}$ and the $\mathrm{TM}_{01}$ and $\mathrm{TE}_{01}$ modes at $1558 \mathrm{~nm}$ these areas are calculated at $236 \mu \mathrm{m}^{2}$ and $234 \mu \mathrm{m}^{2}$, respectively. Hereby indicating that the Raman gain is similar for these two modes. The $\mathrm{TM}_{01}$ and $\mathrm{TE}_{01}$ are inherently polarization preserving [4], hence when the signal are in either of these two HOMs the strength of Raman scattering becomes independent of polarization walk-off. The effective Raman area when the signal is in the fundamental mode is $102 \mu \mathrm{m}^{2}$, however due to polarization walk-off the Raman scattering strength is reduced by a factor of two, which means that the gain is expected to be $15 \%$ higher when the signal is in the fundamental mode compared to the HOMs. However, it was observed that the gain was higher for the HOMs, this is expected to be caused by the large germanium concentration in the outer ring of the index profile, see Fig. 1b, since this is known to increase Raman scattering [5].

In summary, the intermodal on-off Raman gain was measured between full vectorial modes in a specialty designed fiber. By pumping in the fundamental mode approximately $3 \mathrm{~dB}$ of gain was demonstrated for both $\mathrm{TM}_{01}$ and $\mathrm{TE}_{01}$ in a $4 \mathrm{~km}$ fiber using $400 \mathrm{~mW}$ of pump power.

\section{Acknowledgment}

The Danish Research Council for Technology and Production Sciences (project 09-066562) is acknowledged for financial support. OFS Fitel Denmark is acknowledged for providing the fiber.

\section{References}

1. M. Ziemienczuk, A. M. Walser, A. Abdolvand, and P. S. J. Russell, "Intermodal stimulated Raman scattering in hydrogen-filled hollow-core photonic crystal fiber," J. Opt. Soc. Am. B 29, 1563-1568 (2012).

2. S. Ramachandran, C. Smith, P. Kristensen, and P. Balling, "Nonlinear generation of broadband polarisation vortices," Opt. Express 18, 23,212-23,217 (2010).

3. R. Ryf and et al., "Mode-equalized distributed Raman amplification in 137-km few-mode fiber," ECOC p. Th.13.K.5 (2011).

4. S. Ramachandran, P. Kristensen, and M. F. Yan, "Generation and propagation of radially polarized beams in optical fibers," Opt. Lett. 34, 2525-2527 (2009).

5. J. Bromage, K. Rottwitt, and M. Lines, "A method to predict the Raman gain spectra of germanosilicate fibers with arbitrary index profiles," Photonics Technology Letters, IEEE 14, 24 -26 (2002). 